\title{
Laparoscopic Treatment of Vermiform Appendix Torsion
}

\author{
Valioulis loannis, ${ }^{1,2 *}$ Papageorgiou Irene,${ }^{2}$ Simaioforidis Vasileios, ${ }^{1}$ Sfougaris Dimitrios ${ }^{2}$ \\ 1 Department of Pediatric Surgery, Agios Loukas Hospital, Panorama, Thessaloniki, Greece \\ 2 1st Department of Pediatric Surgery, G Gennimatas Hospital, Aristotle University of Thessaloniki, Greece
}

\section{ABSTRACT}

Torsion of the vermiform appendix is an uncommon entity in the differential diagnosis of acute appendicitis in children. A 4-year-old child admitted with signs and symptoms of acute appendicitis. At laparoscopy, torsion of the vermiform appendix was found and the appendix was removed laparoscopically. No complications occurred during the postoperative period.

\section{Key words: Appendix torsion; Laparoscopy; Children.}

Correspondence*: Valioulis loannis, 1st Department of Pediatric Surgery, G Gennimatas Hospital, Aristotle University of Thessaloniki, Eth. Aminis 41, 54635 Thessaloniki, Greece

E-mail: ivalis@otenet.gr

Submitted: 29-08-2017

Conflict of Interest: None
(C) 2017, loannis, et al

Accepted: 25-10-2017

Source of Support: Nil

This is an open-access article distributed under the terms of the Creative Commons Attribution License, which permits unrestricted use, distribution, and reproduction in any medium, provided the original work is properly cited.

\section{INTRODUCTION}

Torsion of the vermiform appendix (VA) is a rare pathologic condition that mimics acute appendicitis. From the first description by Payne in 1918, approximately 17 cases have been reported in children so far.[1-4] We report a case torsion of the VA which was managed laparoscopically.

\section{CASE REPORT}

A 4-year-old boy was admitted with acute abdominal pain and vomiting for the last 12 hours. On examination, he was febrile with tenderness in right lower abdominal quadrant. Blood count showed leukocytosis $\left(13,800 / \mathrm{mm}^{3}\right)$ with predominant neutrophil levels $(75 \%)$. The initial diagnosis was acute appendicitis. A three port technique was used. Inspection of the caecum showed a gangrenous twisted VA (Fig.1). The peculiarity of this case is that the tip of the VA was firmly adhered to the terminal ileum. When tip of the VA was freed it resulted in spontaneous clockwise detorsion of about $270^{\circ}$.

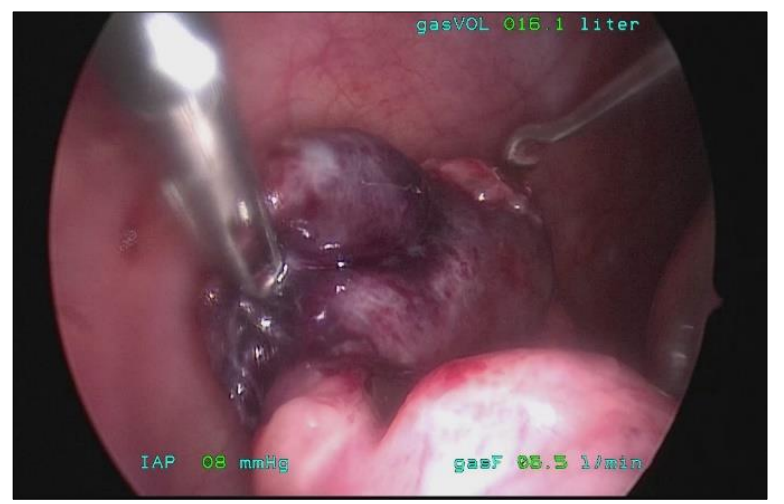

Figure 1: Twisted gangrenous VA, a healthy base proximal to the twist is apparent.

VA was then resected between endoloops as its base proximal to the twist was healthy. VA was extracted in an endobag, through the umbilical incision. Postoperative course was uneventful. Histopathological report showed acute gangrenous appendicitis with necrosis of the appendiceal wall, complete disruption of its architecture and hemorrhagic infiltrations. 


\section{DISCUSSION}

The etiology of torsion of vermiform appendix torsion is not known. It is postulated that various pathologies might be responsible. Primary torsion seems to happen more often in children, while secondary torsion is noticed mainly in adults.[5,6] The rotation of the torsion can be either clockwise or anti-clockwise.[7] Clinical manifestations of VA torsion are similar to acute appendicitis. It cannot be differentiated preoperatively and definite diagnosis can be made only at operation. The condition has a male preponderance in children.[2] In our case, physical examination and laboratory tests indicated acute appendicitis and at surgery appendix was found gangrenous.

Consent: Authors have submitted signed consent form and is available with Editorial office.

Authors' Contribution: All authors contributed equally in concept, literature review, and drafting of the manuscript and approved the final version of this manuscript.

\section{REFERENCES}

1. Payne JE. A case of torsion of appendix. $\mathrm{Br} \mathrm{J}$ Surg. 1918;6:327.

2. Kilincaslan H, Gedik AH, Bilici M, Cakir S. Rare case of an abdominal mass presenting as acute abdomen: Torsion of the vermiform appendix. Pediatr Int. 2013; 55,e14-e16.

3. Montes-Tapia F, Quiroga-Gazza A, Abrego-Moya V. Primary torsion of the vermiform appendix and undescended cecum treated by video-assisted transumbilical appendectomy. J Laparoendosc Adv Surg Tech. 2009; 19:839-41.

4. Kitagawa $M$, Kotani $T$, Yamano $T$, Tsurudome $H$, Hatakeyama T, Kuriu Y, et al. Secondary torsion of vermiform appendix with mucinous cystadenoma. Case Rep Gastroenterol. 2007; $1: 32-7$.

5. Wani I, Kitagawa M, Rather M, Singh J, Bhat G, Nazir M. Torsion of vermiform appendix with fecalith: a case report. Cases J. 2008;1:20.

6. Cassie G. Torsion of mucocele of the appendix caused by a carcinoid tumor. Br J Surg. 1953; 41:105-6.

7. Val-Bernal JF, González-Vela C, Garijo MF. Primary acute torsion of the vermiform appendix. Pediatr Pathol Lab Med. 1996;16:655-61. 